\title{
RELIGION AND SCIENCE UNIFICATION
}

\author{
Ph.D. Spyridon I. KAKOS \\ National Technical University of Athens (NTUA), Athens \\ GREECE \\ Email:skakos@hotmail.com
}

\begin{abstract}
Speaking for God has been part of religion for many years. However, science has come in the past few years to question that role or even our very ability to speak about God in general. My goal is to show that dogmatism, under any form, is wrong. And even though dogmatism had for a long time been associated with ill-intentioned religion, nowadays science has replaced religion in the throne of doctrinaire thinking. The point of the paper is to illustrate that one-way thinking is never correct - most of the times a combination of science and religion, measurements and theoretical thinking, logic and intuition, is required to draw a conclusion about the most important philosophical questions. The paper establishes that exact sciences can be very useful, but they also have limits. The Religion-vs-Science problem is a pseudo-problem; logic and evidence can easily be used to defend theistic views. Both science and religion use common tools and methods and can be unified in a new way of thinking. This paper sets the foundations on how this can be achieved. The conclusion is that science and religion both complete our knowledge for the world, our understanding of humans and our purpose in life. Speaking about God is part of science as well as of religion. Only when we think of God as theologians and as scientists at the same time can we fully reach Him...
\end{abstract}

Keywords: religion; science; science-religion controversy; science philosophy; religion philosophy; God; theism; logic; dogmatism; materialism; axioms

\section{INTRODUCTION}

Figure 1: God the geometer ${ }^{1}$

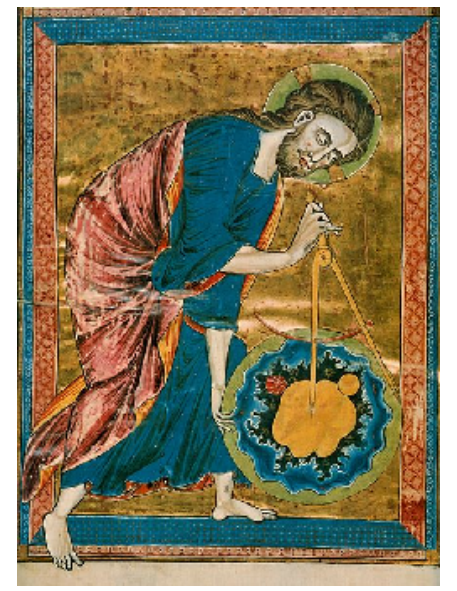

Science and Religion are treated by some people as contradictory ways of thinking. This cannot be further from the truth. Without claiming that I hold the key to the "ultimate truth" (if such thing even exists in philosophy), I will analyze the philosophy underlying both and show that these two ways of thinking are not in conflict, but two sides of the same coin. You can never know life fully, unless you see the cosmos from both perspectives.

The existence of God can be proved by both the tools of logic and faith, or to be more exact: the one cannot fully exist without the other. Religious people are some of the greatest scientists of all times. Science and religion do not solely rely on logic and faith respectively. In an era when the new advances of

\footnotetext{
${ }^{1}$ Source: Wikimedia Commons. Retrieved from

https://commons.wikimedia.org/wiki/File:God_the_Geometer.jpg
} 
science surprise us every day, religion stays powerful and current. That is not without a reason. No matter how much science advances, there will always be metaphysical questions that their answer can only be found in other ways; not because of current gaps in our knowledge but because of deeply inherent limitations. Science cannot tell us anything about how and why we feel sad from hearing a song or sense joy from seeing an old friend, let alone about other more profound metaphysical issues - like what "I am" means. Modern science does not have human as part of the picture it tries to create and that makes it even more demanding for all of scientists to change their way of thinking. The meaning of life cannot be found inside a lab. Logic is a scientific tool as much as experimenting is. And there are a lot of interesting conclusions about our life and our purpose in life that logic has led to. It is important to understand that for science and religion to coexist harmonically, it is not only religion that has to be careful not to interfere with the things science investigates (i.e. physical phenomena). Science must also be very careful not to have philosophical (most of the time anti-religious) assumptions undermining its work.

Despite the (illusionary) science-religion "war" that some people like Dawkins are trying to make us believe that exists, the truth is much more different, simpler and friendlier. Few people realize that the ancient Greeks, who are regarded as the genuine first free thinkers (free from what? - that is the important question) of all time, actually had a religion. Because at the end one realizes that any thought must be based on something. And we should not forget that Christianity was first willingly adopted by those founders of Logic and true Science, the Greeks.

All the Greek manuscripts of Aristotle and Plato, were saved from the passage of time by the Greek Orthodox Christians in the Byzantine Empire and the Islamists Arabs of the medieval times. If you read about ancient Greek philosophy today it is because of a monk devoting his whole life into studying that philosophy in a monastery. It is characteristic that the "priest" of modern atheism, Richard Dawkins, is a professor at the College of St. Mary! So much "war" is going on between religion and science, that religion has created a college for its greatest enemy to teach.

So perhaps there is not only white and black, but other colours as well. The main points of a Religion and Science unity that exists but still eludes most people today, are depicted below.

\section{SCIENCE FOR THE "HOW", RELIGION FOR THE "WHY"}

The realm of exact sciences ${ }^{2}$ is the physical phenomena world. On the other hand, questions like "what is our purpose in life", "why do we exist" or "what is reality" are out of science's scope (see Conclusions for more on that).

Science deals with the 'How', while religion deals with the 'Why'. These are two interdependent and supplementary elements. Even if science finds out how every cell of the human brain functions, it will still haven't discovered why it works that way. The "first cause", the beginning of existence is outside of science's scope. One could say that science deals with the natural world and the natural phenomena while religion with the supernatural phenomena ${ }^{[1,2]}$. That is why both science and religion are needed for the quest of truth. Religion deals with questions science can never answer as the famous ignoramus et

\footnotetext{
${ }^{2}$ I refer to the physical/ exact sciences with the term "science" in this article from hereon - except when stated differently - for simplicity purposes.
} 
ignorabimus $^{3}$ of the German physiologist Emil du Bois-Reymond states ${ }^{[3]}$. And although Hilbert attempted to deny that there are things we will never know, Gödel with his incompleteness theorem proved that Emil du Bois-Reymond was finally right.

It is also very important to understand that science and religion are both based on some kind of faith. Science on the faith that an ultimate truth exists and that logic can reveal that ultimate truth and religion on the faith that an ultimate purpose (and, thus, God) exists (what is interesting to note here is that even though Logic has been proved by Gödel that it cannot prove the truth people still believe in it with no questions asked). Throughout science's history, science had God as its starting point. The notion of us, humans, being made in the image of God gave scientists like Newton the power and will to try to understand the universe; if we are made in His image, then we have the ability to understand His creation people thought from the time of Saint Thomas Aquinas. On the other hand, religion has God as its ending point. It tells us how to behave and act in this world so as to earn a place in the "other" world. Science does not deal with problems of ethics at all. It may tell you how a nuclear bomb explodes, but it has nothing to say about whether you should use it and when. Science deals with measurable things, while religion with things that cannot be measured. And the latter (things for which we cannot speak scientifically) are the ones which distinguish us from animals.

Blaise Pascal tried to make us see the cosmos with our heart. Wittgenstein warned us that the things which matter lie not in this world. And as Albert Einstein eloquently said, "Science without religion is lame, religion without science is blind".

\section{LOGIC ARGUMENTS FOR THEISM}

Many people are empiricists or materialists and deny the validity of theism or the very existence of metaphysics as a valid sector of knowledge. But what we must not forget is that every opinion or philosophical system (both the theistic and the atheistic ones) are based on unproven assumptions and axioms. There is no such thing as 'free' thinking, if by 'free' we mean 'absolutely objective and without any assumption'. Everyone should at least try to know these axioms and once they do, they will understand that the assumptions and axioms required for the belief in the existence of a God are much less in numbers and much less difficult to justify than the assumptions and axioms required to believe in "randomly generated life in a universe which just happened to exist for no particular reason". Some of the arguments in favor of a more theistic view of the cosmos are summarized below. In the process, some of the limitations of science will be revealed.

\subsection{Definitions}

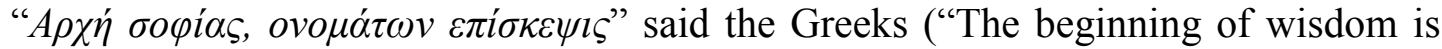
the definition of terms"). Thus, an attempt to define the terms for which we talk about is absolutely necessary before we begin the analysis of arguments in favor of theism.

\section{Metaphysics}

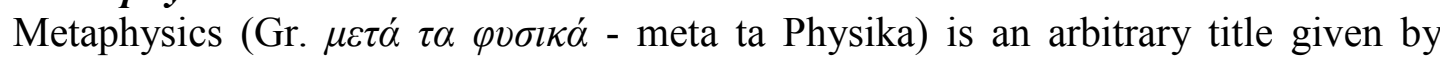
Andronicus of Rhodes, circa 70 B.C. to a certain collection of Aristotelean writings. Traditionally given by the oracular phrase: The science of being as such. To be distinguished from the study of being under some particular aspect; hence opposed to such sciences as are concerned with ens mobile, ens quantum,etc. The term "science" is here used in its classic

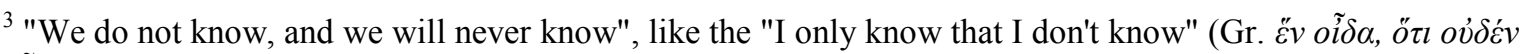
oĩ $\delta \alpha$ ) of Socrates.
} 
sense of "knowledge by causes", where "knowledge" is contrasted with "opinion" and the term cause has the full signification of the Greek cause (Gr. alti $\alpha$ - aitia). The causes which are the objects of metaphysical cognition are said to be "first" in the natural order (first principles), as being founded in no higher or more complete generalizations available to the human intellect by means of its own natural powers. Secondary and "derivative meanings: (a) Anything concerned with the supra-physical, like "metaphysical healing", "metaphysical poetry", et cetera. (b) Any scheme of explanation which transcends the inadequacies or inaccuracies of ordinary thought ${ }^{[4]}$. From that perspective, metaphysical issues are closely related to things existing without any prior cause - look at the "First Cause" argument below for more details and analysis on that.

\section{I can believe anything, provided that it is quite incredible.}

\section{"Believe"}

Oscar Wilde, The Picture of Dorian Gray, 1891

Because the word "believe" has been misunderstood many times, I would like to make a clarification on the way I use it in this article. From my point of view, "believe" does not mean either "know" or "I am certain that this is it". When I say, "I believe" I use the word with what seems to be the dictionary definition of the word: I have some data to point me towards one conclusion, but which are not enough to make me certain (in that case I would say "I know"), so I say, "I believe this is it" based on that data and on some logical arguments. I do not use the word "believe" in the version of "this is how it is, and I censor all other opinions". For example, when someone says, "I see clouds, so I believe it will rain", he is not promoting any religious ideas. He is just making some (probably) valid conclusions (that may even be called scientific), but he uses the word "believe" instead of "I know" because he is not absolutely $(100 \%)$ certain. And this is also a good point to clarify that the only thing science has proved is that it cannot prove anything (see Gödel's Incompleteness Theorem). Our conviction that we can prove something is one of the most fundamental beliefs that persists in the minds of humans.

\section{"Being"}

The hardest questions are the simpler ones. Most philosophy is built on top of the that great question that troubled Heidegger so much: what "Being" actually is, what does it mean? We use it all the time and yet we find it impossible to define. That question about what reality is, is what triggered the creation of the world of the Ideas of Plato, the "Unmovable Mover" (Gr. Akívnto Kıvoúv) of Aristotle or the ego of Freud. All philosophy is based on that question. And Heidegger was right in saying that we have forgotten how important it is ${ }^{[5]}$. All fields of science are failed attempts to get away from the difficulty of that question by breaking it and transforming it to many others. However, the fact that we have broken down the question of "Being" into many smaller ones, does not mean that we have made any real progress. Instead, we have even forgotten the importance of the question. "Being" is something we cannot define. Heidegger tried but failed, but he did show some of its properties ${ }^{4}$. And this failure could be the basis of all the great philosophical problems we currently face. The word here is used in the way we all understand - but cannot actually

\footnotetext{
${ }^{4}$ See George Steiner, Martin Heidegger, Fontana Press, 1978, for a description of the main conclusions of the work of Martin Heidegger.
} 
define in detail - of what being is: I exist, I am, I feel, breath and love, I hate, and I cry. It is me. I exist. I am $\mathrm{me}^{5}$.

\section{Faith}

Faith is a belief in the trustworthiness of an idea that has not been proven beyond the shadow of a doubt. However, this does not mean that faith in something is based on completely nothing else than imagination. Faith in the truth of a syllogism (e.g. that there is a First Cause) can be based on both evidence and logic. And let's not forget that all axioms (on which any scientific theories are based upon) are taken for granted based on faith. Faith that they will help build a solid scientific model. Faith that they will provide the basis for a theory which explains what we observe. Faith that they are somehow close to the objective truth (which we believe it exists out of faith again).

\subsection{A higher purpose exists}

I believe (i.e. "my logic dictates that to me after I have examined many facts about the universe" and not "I think so with no supporting logic or evidence whatsoever") that there is a higher purpose in life. And this purpose - existing way above the level of matter could have only been set by a perfect and transcendent being like God. Since everything we do in life we do it with a purpose in mind ${ }^{[6]}$, I find it illogical and highly improbable that our life has no purpose. This is known as the teleology argument.

I don't know what that purpose is and I may never find out. But many things we know and experience indicate that something of "higher essence" is part of our existence that we are partly made of something more than dust. We are luminous beings, not crude matter. Science may never understand why we come to tears when we listen to an old favorite song (even though it may explain thoroughly the chemistry and the mechanism of tears), why we laugh, why we may love someone so much that we may give our life for (and I am not talking about the love a mother has for her child - which may be explained by the theory of evolution since the mother has that love to protect her child -but to all other kinds of love a human may exhibit, like the love a human has for his friend et cetera), why we are good, why we exhibit altruistic behavior by helping people unknown to us while at the same time risking our own lives (and without ever wanting that to be known so as to get a reward of some kind), why human strives for creation, writing, poetry, why we may give our lives for higher ideas like freedom, why people kill themselves (if surviving was the ultimate thing we had in mind like the theory of evolution implies, then we would never even consider killing ourselves) and so on.

It is logical to think that these phenomena are derived from something more than simple matter, something beyond what we see and feel. Unless someone finds it logical to believe that a set of lifeless electrons and protons can "decide" to be destroyed for a separate set of electrons and protons. As Pascal reminded us "Jesus says: Console yourself, you would not seek me, if you had not found me".

\subsection{The First Cause argument}

The Universe is intelligible and that logically means (at least that is was this meant to

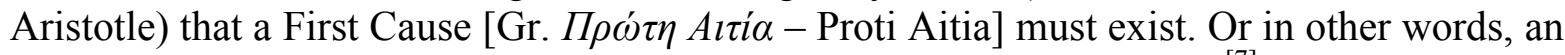
Unmovable Mover must have set the world in motion in the first place ${ }^{[7]}$. Science from the

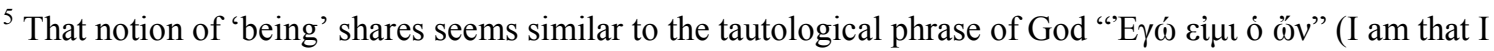
am). This is the only thing we can be certain of and it stems out not from any logical explanation of the world but from an irrational belief that we "are". In that sense our logic seems more irrational since it cannot account for that fundamental knowledge we all share. (Spyridon Kakos, Harmonia Philosophica: The philosophy of the

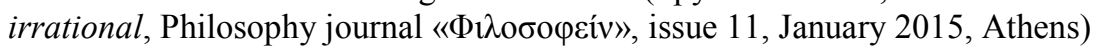


beginning of time tries to find the causes of all phenomena, so it is rather ironic that some scientists completely reject the idea of an initial cause - even as a possibility. It is not logical to say that every event has a cause, but that the universe itself has none. After all, when examining an event, e.g. a glass of water that falls on the ground, you try to find the initial cause. If you say that "the glass fell because of the law of gravity" you would have "cheated". You did not find THE cause, you just stated the first-most immediate cause. For your analysis to be complete, you must find the cause of the law of gravity, the cause of that cause etc. If no initial cause exists (God? - the name plays no role), then actually the simple phenomenon of the glass falling has no cause at all. The world would stop from being intelligible.

As the "sufficient cause" argument of Leibnitz states, there must be sufficient reason for something to "be". So, there must be some reason for all the universe to exist, instead of nothing.

In summary the "First Cause" argument is as follows:

1. The cause of existence for something can lie outside of (so we talk for "possible" things) it or inside it (so we talk for "necessary" things). A child is a "possible" thing: it requires an "outside" cause to exist (i.e. its parents). God (as defined by religions) or the ever-existing universe (as described by Heraclitus) are "necessary things (i.e. the cause for their existence lies inside them).

2. Something can exist or not-exist. Something exists only if there is "sufficient reason" for it to exist. This is the only way that existence can be justified against the possibility of non-existence. A child can exist or not-exist. If it exists, it does so because of a sufficient cause: its parents and their decision to make children.

$3.1+2 \Rightarrow$ Universe requires a cause of existence.

4. Nothing can be created from nothing. If at some moment (i.e. before the Big Bang) there was nothing, then nothing should exist now either. So, the universe either exists for ever or was created at some point.

5. If the universe existed for ever, it does not need an "outside" cause for existence - it is "necessary". Otherwise it requires an "outside" cause for justification of its existence.

6. All the things we observe are "possible" (i.e. they require an "outside" cause to exist). For example, I exist because of my parents. This text exists because I write it.

7. The universe exists and is the sum of all things that exist in it.

8. $6+7 \Rightarrow$ Universe is "possible", so it needs an "outside" cause to exist. This cause, we call the "First Cause".

9. Everything has a cause. So the First Cause must also have a cause.

10. If the First Cause has an outside cause, then we end up with an infinite series of causes $\Rightarrow$ No First Cause exists.

11. The conclusion 10 is not correct, since it does not agree with 8 .

12. $8+11 \Rightarrow$ The first cause does not need an outside cause for existence. The first cause is "necessary".

No arrogant claim of scientists that "we know what caused that phenomenon" can escape dealing with the First Cause. What we seem to know is usually only the first or second most immediate cause of a physical phenomenon and nothing more. However, that means that we do not actually "know" the true initial cause of the phenomenon. Science is an excellent tool to examine reality but unfortunately is has its limits. And these limits seem to pose an impenetrable wall at where the explanation of the essence of our existence lies. If we 
are to accept that we can understand the universe, then we cannot ignore the implications of that understanding that we everyday "feel"...

The First Cause argument is one of the most well-known and well formulated arguments in favor of a God. Atheists (with Hume being one of the examples) in their attempts to discredit it or deny it have reached to the point of denying the very existence of "causality" in the Universe. Some claim that "we are not sure that causality exists, why not have an infinite series of causes?", while probably forgetting that the whole structure of science is based on the very existence of causality. Some others claim that no causality exists in quantum mechanics, so in the beginning of the universe no causality existed, and an infinite series of cause is a valid theory. These people forget that even for the complicated and stillin-debate field of quantum mechanics where more than ten interpretations exist, most known scientists believe a deterministic (i.e. including the notion of causality) interpretation $[3,8,9$,

${ }^{10]}$. It is important to remember that the point here is not if causality exists or if the argument can persuade everyone or not. The point is that there is a logical background in the arguments for the metaphysical realm of God, that the metaphysical can be part of human intellectual. In any case what is "logical" is a matter of choice: People doubt that there can be a First Cause which needs no cause of its own, only to "prove" that the whole cosmos itself can exist without a cause. Opening the door to a cosmos without causality more problems for science than for religion. In a world without causality the existence of a First Cause is no longer a problem, however all scientific theories must be rewritten to account for that new "reality".

\section{3 "A priori" and "a posteriori" knowledge}

Empiricists deny the existence of knowledge that does not come from experience ("a posteriori" knowledge is the knowledge based on experience). In other words, they deny the existence of any "a priori" knowledge. However, Kant postulated that there can be human "a priori" knowledge. For example, the ' $1=1$ ' syllogism is an a priori knowledge - it is independent of any present, past or future experience. The argument "if $\mathrm{A}$ is true and $\mathrm{A} \Rightarrow \mathrm{B}$, then B is true" is also an a priori knowledge. We seem to have it without someone teaching us so. We understand it is true (even though it may not be, never trust what you already "know"). Another example comes from our experience in science of counting: when we count or measure we use the underlying notion of quantity. That notion should be somehow "embedded" in us before we start counting. It is an a priori knowledge on which we base all other knowledge we acquire ${ }^{[2,11]}$.

The sum of a priori knowledge is knowledge that exists without prior cause something like the First Cause stated in the above sub-chapter. That a priori knowledge (e.g. of the notion of quantity or the notion of quality, according to Kant) is the basis of our own understanding of the universe. And the very existence of such a kind of knowledge states that "something" gave us that knowledge. That "knowledge with no causes" is what the area of "metaphysics" is all about.

The attempt of some empiricists to explain our a priori knowledge with terms of evolution fails. Some people claim that what we seem to know before any experience of ours, is actually the encoded knowledge of our ancestors in our genome. Again, finding a possible immediate cause does not mean that we know the true (initial) cause of a phenomenon (see above sub-chapter for more on that). So, the question in this case is simply transferred one "level" backwards: How did the first humans know how to count if they did not have an a priori sense of the notion of quantity? 


\subsection{Ontological arguments}

Many thinkers have attempted to prove the existence of an all-powerful being (like the one religions call God). These attempts are interesting not because they prove something beyond the shadow of a doubt (there are indeed logicians who think they are correct, but there are also others who think otherwise ${ }^{6}$ ), but because the show that logic can be a tool that leads to God. One of the greatest logicians of all times, Gödel, has documented such an ontological argument ${ }^{[12]}$.

The argument initially uses the following axiom.

Axiom 1: It is possible to single out positive properties from among all properties. Gödel defines a positive property rather vaguely: "Positive means positive in the moral aesthetic sense (independently of the accidental structure of the world). It may also mean pure attribution as opposed to privation (or containing privation)"

We then assume that the following three conditions hold for all positive properties (which can be summarized by saying "the positive properties form an ultrafilter"):

Axiom 2: If $\mathrm{P}$ is positive and $\mathrm{P}$ entails $\mathrm{Q}$, then $\mathrm{Q}$ is positive.

Axiom 3: If P1, P2, P3, .., Pn are positive properties, then the property (P1 AND P2 AND P3 ... AND Pn) is positive as well.

Axiom 4: If $\mathrm{P}$ is a property, then either $\mathrm{P}$ or its negation is positive, but not both.

Finally, we assume the following axiom:

Axiom 5: Necessary existence is a positive property (Pos(NE)). This mirrors the key assumption in the respective Anselm's ontological argument.

Now we define a new property G: if $x$ is an object in some possible world, then $G(x)$ is true if and only if $\mathrm{P}(\mathrm{x})$ is true in that same world for all positive properties $\mathrm{P}$. G is called the "God-like" property. An object x that has the God-like property is called God.

From axioms 1 through 4, Gödel argued that in some possible world there exists God. He used a sort of modal plenitude principle to argue this from the logical consistency of 'Godlikeness': in a possible world it is certain that an object with all positive properties does exist. Note that Godlikeness is itself positive, since it is the conjunction of the (infinitely many) positive properties.

Then, Gödel defined essences: if $\mathrm{x}$ is an object in some world, then the property $\mathrm{P}$ is said to be an essence of $\mathrm{x}$ if $\mathrm{P}(\mathrm{x})$ is true in that world and if $\mathrm{P}$ entails all other properties that $\mathrm{x}$ has in that world. We also say that $\mathrm{x}$ necessarily exists if for every essence $\mathrm{P}$ the following is true: in every possible world, there is an element y with $\mathrm{P}(\mathrm{y})$.

Since necessary existence is positive, it must follow from Godlikeness. Moreover, Godlikeness is an essence of God, since it entails all positive properties, and any nonpositive property is the negation of some positive property, so God cannot have any nonpositive properties. Since any Godlike object is necessarily existent, it follows that any Godlike object in one world is a Godlike object in all worlds, by the definition of necessary existence. Given the existence of a Godlike object in one world, proven above, we may conclude that there is a Godlike object in every possible world, as required. In simpler words: Since a Godlike object exists in one possible world, then it necessarily exists in all other possible world (since "necessary existence" is one of its positive properties).

\footnotetext{
${ }^{6}$ In any case let's not forget that Gödel's Incompleteness Theorem states and proves that nothing can be proved beyond the shadow of a doubt. There will always be 'truths' which cannot be explained based on a given set of axioms.
} 
From these hypotheses, it is also possible to prove that there is only one God in each world: by identity of indiscernibles, no two distinct objects can have precisely the same properties, and so there can only be one object in each world that possesses property $\mathrm{G}$. Gödel did not attempt to do so however, as he purposely limited his proof to the issue of existence, rather than uniqueness. This was more to preserve the logical precision of the argument than due to a penchant for polytheism. This uniqueness proof will only work if one supposes that the positiveness of a property is independent of the object to which it is applied, a claim which some have considered to be suspect.

Again, the same thing which applies to all other arguments applies here as well: one might surely disagree with it. But this is not of importance. The critical point here is that some other logicians agree ${ }^{7}$. So even though this argument has not solved the great mystery of them all, it has given us a great lesson: Logic is not a tool for atheism only, it is a tool for theism as well.

Some people argue that Gödel had defined "positive" too vaguely. "Why should existence be a positive property?", they ask. My answer to that counter-argument is rather simple: Let us imagine that, for the sake of the argument, "existence" is a "negative" property. Then all people should stop worrying about dying, since "not existing" is something good! In that way all great philosophical problems of humans will be solved in a strange but clearly decisive way.

\subsection{The argument from Design}

The Universe seems to be designed. Modern cosmology has discovered that as many as ten parameters are set to exactly the necessary values so as to have a universe that sustains life ${ }^{[13]}$. This seems to be indication of a "Design" by many. Others of course do not reach to the same conclusion: such a set of fine-tuned parameters could be (according to a very extreme position) a result of pure luck. A coincidence of cosmic proportions. Modern cosmology is the modern theology.

The point to note again is not the fact that this is a final argument proving God beyond the shadow of a doubt. Every phenomenon can be interpreted in different ways. Most of times the underlying philosophical stance of the observer is what dictates him what to conclude. However, what one should understand from that argument of "Design" is the fact that observations and logical analysis can provide the basis for faith in God's existence. Whether you agree or not with this logical analysis does not destroy the value of that argument per se.

\subsection{Other arguments}

The existence of "free will" can also show the existence of God. Few people have thought about the implications of the existence of free will. In a fully materialistic ${ }^{8}$ world governed by universal absolute physical laws that define everything there is no room for free will. The only way to justify the existence of free will is to base that existence on "something" that does not follow the physical laws (which are the ones which make everything predictable in the universe). The foundations of free will must be set on that "something" that does not follow the logic "initial conditions" and the "physical rules" (thus leading to predictable behavior). In that way free will opens the path for the only being that could deviate from the path of the physical laws - God (as a "first cause" - see above respective argument).

\footnotetext{
${ }^{7}$ What is logic, but the view held by the majorities? asked William James.

${ }^{8}$ Materialism is a philosophical dogma believed by many scientists today, who forget that no one has proved or shown that only matter exists in the cosmos - let alone define what matter is. [14]
} 


\section{LOGIC AND NOT ONLY FAITH}

Before someone counter-argues that all these are indications and not scientific proof, I will argue that saying that is completely wrong since it is based on numerous assumptions the greatest of which is that this claim takes for granted that we know what is objectively true even though we do not. It is a great mistake of the atheists and the agnostics to claim that every argument in favor of the existence of God is "not-logical" or simply false. The job of every scientist and open-minded person is to question everything. It is not thus logical to say that "we can and must question everything and we must not be dogmatic", but have exceptions to that rule. If we are to question everything, then the dogmas of the modern materialistic age must be questioned too.

We must bear in mind that for things that relate to all these metaphysical questions (like what is our purpose in life), there is little hard (i.e. not like "I watch the universe and calculate the law of gravity") evidence to rely on. Metaphysics is the realm of "nonmeasurable" things which are outside the scope of science by definition. Although one could have some hard data about the universe's structure and way of working, we have to rely on "soft" evidence and common (i.e. not strictly defined mathematical) logic to make the "leap" required in order to explain things in the metaphysical world. The abovementioned indications are all we've got.

And we must note that at least the ones that argue that there is a purpose in life have some indications to base their arguments on - while the ones that claim there is absolutely no purpose in life do not even have indications, they just have speculations. The theory of evolution is based on some fossil. And it really explains well some things: e.g. how some species evolve and change over time. However, explaining how fish evolved and went to the land, doesn't mean that we have explained there is no purpose in life or that God doesn't exist. This is a huge logical leap that is not supported by any evidence or logic.

Humans have more than one tools to reach truth. We have our feelings and our intuition. We don't know whether our logic or our feeling/ intuition are better guides for the truth. Many mathematicians have used their intuition to formulate theorems that every mathematician believes as true today but are still unproved. Science and religion, religion and science should work together to fill in the pieces of the puzzle of human existence. Until we have some better clues, we must rely on the indications we have and not to "believe" we have the correct answer to everything.

\subsection{Faith in science}

Scientists use logic to reach conclusions, based on observations data. These conclusions are based on a series of very subtle underlying beliefs - beliefs based on faith to a lesser or greater extent. Some of the beliefs scientists rely upon in order to reach to conclusions and formulate scientific models, are depicted in the following list:

1. Belief that all that exists in Universe is matter and the physical laws. We must not forget that materialism is an underlying dogma of most of today's scientists and not a truth that has been proved ${ }^{[6]}$.

2. Belief that Logic as a tool works correctly: This belief is used mainly in physics, since in mathematics it has been proved that logic has flaws and inconsistencies (see Russell's paradox and Gödel's Incompleteness Theorem).

3. Belief that all physical laws apply to the whole universe: For example, we can see that gravity applies to our solar system and we believe that the same gravity applies also to 
galaxies we have not yet even observed. Modern observations have started hinting at a law of gravity which is not universally homogeneous 9 .

4. Belief that logic induction leads to correct conclusions: This is a subset of the belief in logic and the basis of most modern physics. When we observe a physical phenomenon and then verify that the same phenomenon takes place in a second and a third experiment, we conclude that the same phenomenon will occur also in the next experiment. But we cannot be sure about that. It is highly possible that we have observed the three exceptions to the rule and that all the other experiments we will conduct will result in something different.

5. Belief that our senses work correctly: This is of the uttermost importance, but we insist on forgetting it. Our whole perception for the world is based on our senses. We do not know how close is the world we feel via our senses with the "real" world. Take for example the colour red. We see "red", so we conclude that it exists. However, we forget that most animals do not see red. So, what is the "real" thing after all? Does red exist or not? According to the myth, Democritus chose to pull out his own eyes so that he was not deceived by his senses. We chose to blindly trust what we see.

6. Belief in the fellow human: This may sound weird, but it is the basis of our scientific society. When a scientist publishes a conclusion all other scientists believe him just by trusting his word. If a paper is published on a scientific journal with prestige, then it "must" be true. However, we have seen many times scientists tampering with their data and posting fake "groundbreaking" conclusions. When the historians listen to an eyewitness who says to them what has happed at a given period, they just trust him. If you do not test the conclusion yourself, then your belief in what the other scientists says is mostly based on the grid of human trust and only that.

7. Belief that all things are measurable and that all phenomena can be reproduced in a laboratory. I can easily think of a very important case of a phenomenon which could have occurred only once and which is thus unable to be reproduced: the creation of the universe with the Big Bang.

8. Belief that the axioms on which we base our theories are "true". This is the most important faith of them all. We must never forget that all theories are based on axioms (like the ones mentioned above) and that no axiom is proved. Change the axioms at will and you will end up with a different theory! Having axioms is not a bad thing per se (to be exact, there would be no science without axioms). What is bad is forgetting that your axioms are unproven and arbitrarily selected.

The abovementioned beliefs tend to transform to dogmas when we forget that we are using them. When we forget that our conclusions are based on such beliefs that we cannot be sure if they are true or not, then we become dogmatic and stop being true scientists. We must acknowledge our limitations and move on by embracing them, not by ignoring them.

\section{MISUSE OF SCIENCE}

Many modern-day atheists use science to serve their own purposes. No better example of that can be found but in the case of the Theory of Evolution. Those people (with Richard Dawkins in the first line) try to establish the idea of a "war" going on between science and religion, something which is simply not true. After showing the limitation of science and how there can be logical arguments to support the existence of God, this part

\footnotetext{
${ }^{9}$ See for example the modified Newtonian dynamics (MOND) proposed by Mordehai Milgrom in 1983.
} 
focuses on how some arguments against God may actually be derived from a misguided use of science.

\subsection{New scientific findings}

Mainstream scientists tend to rely on a simplified view of science philosophy for various concepts. For example, they take it for granted that the cause must exist before the event that it causes. However new findings in science point towards a fresh look to our world. Teleology (existence of a purpose - Gr. $\tau \dot{\varepsilon} \lambda o \varsigma$ ) seems to find its way through physics - not always in a straightforward way. No scientific theory indicates that the cause must always exist before the result. Quantum mechanics experiments - e.g. the experiment of the two holes ${ }^{10}$ - show that an electron may "decide" whether it behaves like a particle or like a wave during its course only after a human has observed it (a.k.a. the 'Observer problem'). And it "decides" for its nature for the entire length of its existence - not only after it has been recorded in a particle detector but even before that. The world laws of physics are not so platonic - perfect as once we thought they were. That, along with the fact that the human watching the experiment of the two wholes help the electron determine its existence, creates more room for teleology: if the human decides for the electron, maybe he decides for the universe laws as an observer of these as well (or, in other words, the planets move the way they move so as to obey their "purpose" of behaving in the way the human observer wants them to)? Like the electron that its whole existence is determined by its goal (purpose) to look like a particle or wave at a certain point of time, the human life may be the way it is because of a higher purpose we have in the universe, or because of a higher purpose the universe has for us. Evidence from recent research hint that our mind could be the one shaping reality ${ }^{[15]}$. Maybe the universe has the higher purpose to be set by us and we have the higher purpose to reach the higher mental level and connect to the "universe" itself (Gr. $\theta \varepsilon \dot{\varepsilon} \omega \sigma \eta$ - theosis). We still do not know, but the window for the truth is open. And it does not seem like a "logical" window at all.

These findings are not the only ones which may support a different view on things. As science progresses and as scientists analyze the cosmos, new questions come forward. For example, the laws of physics seem to have limits. The universe has a specific amount of processing power (if you look at every particle as a bit of information, then the universe is like a giant computer - according the theory of information nowadays) and this means that it (the universe) can calculate for example the position of planets up to a specific decimal point. Higher accuracy has its limits even for the cosmos itself. And yet, we have the belief that we can eventually understand and discover everything. Is that a religious belief or inherent arrogance of modern science?

\subsection{Evolution as an accident}

The best example of science misuse is the attempt to apply the theory of evolution to philosophy, to show that there is no purpose or First Cause. For some people, if we accept the sayings of the theory of evolution then there is not purpose in life, since we are an accident of nature. We exist because we just happened to exist. And why do we exist? For no reason. This is in every way deeply illogical: by saying that we exist with no purpose in life, you nullify the value of human life itself, you tell everyone that being a human or a banana is more or less the same (we share $50 \%$ of our genome with the banana and $60 \%$ with flies). And you choose to blatantly ignore all the indications I mentioned above regarding our

\footnotetext{
${ }^{10}$ Also known as the 'double slit' experiment. The original experiment was performed by Davisson and Germer in 1927.
} 
nature: if there is no purpose in life and if man is so completely stripped off anything of "higher value", then why do we everyday strive to get out of our body and grow spiritually? In general, this is just a categorical error: these people use a biological theory to explain things which are not related to biology, thus arriving at erroneous conclusions.

Furthermore, some things for the theory of evolution are yet unanswered: How does a system evolve in something more functional over time? We know from physics that every system's entropy ${ }^{11}$ increases over time (law of thermodynamics). How species then evolve by pure chance? Scientific experiments with flies and other insects have shown random mutations over time, but none of these mutations has led to a new species ${ }^{12}$. All in all, the theory is a very good biological theory but with limitations - even in the field it is related to (i.e. biology). In summary, the theory of evolution has showed that it can be used as a tool to analyze biodiversity, but not as a tool to find the ultimate truth about everything concerning life or as a tool to answer philosophical questions.

\subsection{Medicine as "inhumane mechanics"}

The best argument many people find for science is medicine. However, the truth is exactly the opposite: medicine has become so inhumane today that it offers the perfect argument against science ${ }^{13}$.

First of all, medicine is not a science with the proper definition of the term. Science is about creating models for the prediction of systems' behavior in the future via theories. Medicine does not formulate theories in the same way physics do. Medicine is based on observations alone. But making observations and deducing conclusions is not Science. If it was, then baboons watching coconuts falling on each other and breaking apart would also be making "science" as well. Secondly, medicine must not be confused with technology. Seeing something in the ultrasound equipment is not "science" as such. And surely seeing something in the ultrasound equipment is not medicine. Medicine is many things and an indication on the iU22 xMATRIX screen is at the bottom of that list.

Medicine is all about love, it's all about care and compassion, it's about faith and love. Faith in other humans, faith in the value of life as something more than a set of organs working together like a machine, love towards other people, love of existence instead of nothingness. Things which are now longtime forgotten by our modern "scientific" medicine, which mostly adheres to a mechanistic inhumane view of the cosmos. And when we try to analyze the connection of medicine with these notions we may be startled to discover that medicine can be more "unscientific" and more "irrational" than its believers would like to admit.

Empirical observations do help, but again what do they help us about anyway? If we see ourselves as machines then it is surely good that we will live 10, 20, 30 years more. But why would we want to live more? Why should we even care about that? Philosophy has not found any reason why health is better than sickness and we surely do not know if life is better than death in the first place. Sticking into the materialistic mechanistic view of

\footnotetext{
${ }^{11}$ Quantitative measure of the disorder of a system.

${ }^{12}$ In that case it must be noted that the problem of the definition of what constitutes a 'species' is very important. Also known as "The species problem". Is a fruit fly with different shape of wings a new species? It is notable that Darwin's book triggered a crisis of uncertainty for some biologists over the objectivity of species, and some came to wonder whether individual species could be objectively real - i.e. have an existence that is independent of the human observer. (see Johnson, DS April 1908, "Introduction". The American Naturalist. 42 (496): 217)

${ }^{13}$ With "science" in this case I refer to modern science, which choses to be distinct from any other field of human knowledge. In the days before Galileo however, religion and science were not separated as such.
} 
humans will help us treat patients up to a point. Patients need other things though. We are all going to die anyway. Does it matter if we live more or less? Or is it that other things matter more? When examining the foundations of our attachment to life we will discover many assumptions which we cannot answer.

If we are machines, I do not know why we should even care.

Dogmas turn us dead long before we die...

\subsection{Consciousness, the last frontier}

The most important thing man ever wanted to know was "who am I?". And in this quest, he started asking questions about nature, about being, about time, about anything. Modern science has started to analyze the great mystery of consciousness but with little success. Although the analysis of the details of related research falls outside the scope of this article, it is important to note the obvious: Someone cannot find what he does not look for. Modern science has "created" a cold universe with particles and lifeless matter - no wander it cannot "find" human consciousness anywhere. We have defined a place which just exists, and we observe it standing outside of it. There is no place for human spirit inside such a cosmos and that is why all scientific theories researching the subject are in fact chasing their own tails. Many evidence from observations or experiments already point out towards a human mind which is not located or limited in what we call "brain" [16, 17]. That, along with the problems of neurology to substantiate it's claims on clear philosophical grounds (reading brain readings does not mean anything with regards to what is actually happening towards the realization of a thought, who makes that thought and so on), lead me to the conclusion that the problem of consciousness will be the cause of a grand paradigm shift towards less materialistic ways of conducting scientific research.

\subsection{Lessons learned}

All of the above teach us an important lesson: We should not let our dogmas (e.g. "materialism", "theism", "atheism" et cetera) lead our thought. We should acknowledge that we use axioms and at least speak freely about the underlying dogmas of our theories so that other people can judge them properly. The ultimate goal is to try to think without any axioms in mind at all, although this is very difficult to achieve ${ }^{14}$.

\section{SCIENCE DRIVEN AWAY FROM HUMANS}

The most important thing to say about today's science is that science has stopped having human life as its primary focus for a long time now. In its effort to explain everything, it has forgotten that its main purpose is to serve human and improve our lives. By telling people that we are nothing more than dust certainly doesn't help in that direction (although it will certainly grant some people a good funding to go on researching why people are so similar to bananas). If you axiomatically think the world is consisted only of particles and physical laws that govern their behavior, then no wander you cannot find any evidence of spirituality in the universe. If you axiomatically think that there is no purpose in our existence, then it is more than logical that you cannot find any proof for the existence of purpose in the cosmos.

Let us not fall into the trap of some atheists who wish to have a "war" between science and other ways of reaching the truth, like philosophy or religion. Logic is as much a

\footnotetext{
${ }^{14}$ This "thinking without thinking" is what various mystics over the ages hinted about. Letting go of any thought and just accepting the cosmos as it is, seem to be the keys to various methods of meditation. Some Christian seemingly monotonous prayers bear many resemblances to such methods.
} 
useful tool as intuition and instinct are. Many atheists today have tried to make a hero out of Galileo Galilei by distorting the facts around his trial and his general behavior. As philosopher Paul K. Feyerabend says, the case of Galileo was a minor and not-at-all important episode of the life at that time. Galileo had made a promise and he had attempted to hide behind lies. He wanted to reach a compromise and he finally did. Proponents of scientism, in a look for a "hero", managed to change the story of a frightened "con" to the story of the clash between "giants" [18, 19,20,21, 22].

Science must re-unite with philosophy and - as in the times of Aristotle and Plato try to reach truth with a more holistic way of thinking. Science must understand that the dogmas on which it relies could be wrong. Science must understand that not all things are measurable (like moral, emotions, love) and that there are things we will never know via science. Trying to use other paths to the truth seems unscientific but it is actually the most scientific thing scientists can do today.

\section{THE PROBLEM OF HUMAN PROGRESS}

Humankind progresses. We learn new things, we generate new ideas, we read history and try to make the future better. Our society progresses in all sectors. Some Darwinists claim that human progress does not actually exist, that it is a mere illusion. They say that the only real progress is the one conducted via random mutations and natural selection. I disagree. We progress in all sectors, even if this progress is sometimes very slow. Even if someone denies progress' existence in one sector, he will not be able to deny the fact that humans progress in a way in some fields. This progress indicates that we are not only influenced by our environment, but we also influence it back. We are not evolving only by adaptation to our environment (as the theory of evolution claims), but we also evolve via our own free will and make the environment adapt to us. The fact that we design new life forms or improve our own genome via molecular biology, clearly shows that the notion of "design" is something that is not just a theological idea but rather a part of reality. We progress because we have free will and because we are conscious of our ability to formulate our very own optimized designed future. This provides evidence that we are not the same as the other species. Maybe the structure of society dictates how some of our human traits of 'higher essence' - like free will - are expressed, but one cannot deny that humans inherently have some traits of such nature.

And it is important to note that for the last 50 years, the progress that was promised by the materialistic science at the end of the 21 st century was not delivered. In contrast to the recent past when scientists' thought was more holistic, we cannot claim that today we have made substantial progress on many sectors ${ }^{[9]}$. Science today only collects vast amount of data, without suggesting any essentially new theories for the cosmos. Having CD-ROMs and DVDs is not progress. Analyzing terabytes of data is not science, in the sense of the science produced by Newton - it is just analysis.

I certainly hope that will lead science to go back to more holistic ways of thinking, as it used to think back in the good "old" days of Aristotle or at least Albert Einstein. Science needs to become more humane, now more than ever.

\section{POST-MODERN PHILOSOPHY}

Wittgenstein - a pioneer post-modern philosopher - thought that all philosophical problems are misunderstandings caused by the limitations of our language. For example, the phrase "the pig hereres" is neither true nor false. That phrase is nonsense: the words used 
have no meaning. Thus, we cannot claim anything about its truthfulness. In the same way, the phrase "God exists" cannot be true or false either. In that phrase we use the word "God" without knowing what "God" exactly is and the word "exists" without having defined exactly what "existing" means. So, that phrase is nonsense too.

The teachings of Wittgenstein were wrongly used by many atheists to claim that no God exists. The Vienna Circle attempted to make such a misuse and that is why Wittgenstein did not go to their meetings.

The reality is quite different. Wittgenstein in his work Tractatus LogicoPhilosophicus was clear on one thing: the things that are of real importance in life are the ones for which we cannot speak about! We may not be able to answer the question "does God exists?", but that does not mean anything about God's actual existence. And that question - in spite of what many agnostics "believe" - is indeed one of the most important ones: knowing who we are and how we came to be is knowledge we must all have. As Heidegger ${ }^{[23]}$ said, we may not know what "Is" is, but the search for its meaning is what makes us humans.

\section{CONCLUSION}

As the Interacademy Panel (IAP - Global network of Science Academies) stated on an announcement it made for the theory of evolution on 21 June 2006: "Human understanding of value and purpose are outside of natural science's scope. However, a number of components - scientific, social, philosophical, religious, cultural and political contribute to it. These different fields owe each other mutual consideration, while being fully aware of their own areas of action and their limitations. While acknowledging current limitations, science is open ended, and subject to correction and expansion as new theoretical and empirical understanding emerges" ${ }^{[24]}$.

It is also very important to note that when Edward J. Larson of the University of Georgia in USA attempted in 1997 to repeat an older study conducted in 1916 (by the noted psychologist James Leuba) concerning the percentage of scientists believing in God, he was surprised to find out that the percentage remained the same despite the great advances of science. A very stable $40 \%$ of the scientists surveyed (biologists, mathematicians, physicists and astronomers included) answered that they believed in the existence of a God, despite all the astounding scientific breakthroughs in the years that have elapsed ${ }^{[11]}$. What is more, a 2005 survey of scientists at top research universities found that $38 \%$ had a religious affiliation and more than $73 \%$ believe that religions convey important truths. The same study showed that religiosity in the home as a child is the most important predictor of present religiosity among scientists ${ }^{[12]}$. What is more, in the Global Values Survey (that is conducted since 1981) it is shown that the higher the educational level of a person the more possible it is that this person will be religious ${ }^{[25]}$. So being religious is not at all incompatible with being a good scientist as some people are trying to make us think.

People are tired of dogma (religious or scientific) and of cold science as well. As a conclusion one could say that we must stay humble in front of the wisdom of nature, search like a scientist, believe in human and its higher value like a theologist and work all together to discover the truth! Asking the right questions is sometimes more important than knowing the answers... 


\section{REFERENCES}

[1] Museum of Paleontology of the University of California at Berkeley, Science and religion: Reconcilable differences, part of Understanding Science project, Retrieved from https://undsci.berkeley.edu/article/science_religion, 2017-12-01.

[2] A priori and a posteriori, Wikipedia article, Retrieved from https://en.wikipedia.org/wiki/A priori and a posteriori, 2017-12-01.

[3] William E. Leverette Jr., "E. L. Youmans' Crusade for Scientific Autonomy and Respectability", American Quarterly, Vol. 17, No. 1. (Spring, 1965), pg. 21.

[4] Dagobert D. Runes, The Dictionary of Philosophy, Philosophical Library, USA, New York.

[5] Martin Heidegger, Sein und Zeit, in Heidegger's Gesamtausgabe), volume 2, ed. F.-W. von Herrmann, 1977, XIV, p. 586.

[6] Dr. Mary Midgley, "Purpose, Meaning \& Darwinism", Philosophy Now, issue 71, January/ February 2009.

[7] Aristotelian theology, Wikipedia article, Retrieved from https://en.wikipedia.org/wiki/Aristotelian theology, 2017-12-01.

[8] Interpretation of quantum mechanics, Wikipedia article, Retrieved from https://en.wikipedia.org/wiki/Interpretations of quantum mechanics, 2017-12-01.

[9] David T. Pegg, "Causality in Quantum Mechanics", Physics Letters A 349 (2006).

[10] Mauricio Suarez, "Causal Inference in Quantum Mechanics: A Reassessment", Universidad Complutense de Madrid, in Russo and Williamson (eds.) Causality and Probability in the Sciences, London College Texts, January 2007.

[11] A priori and a posteriori, Internet Encyclopedia of Philosophy article, Retrieved from http://www.iep.utm.edu/apriori/, 2017-12-01.

[12] Fitting, M, Types, Tableaus, and Gödel's God, Springer, Series: Trends in Logic, Vol. 12, 2002, p. 196.

[13] Davis, Paul, Cosmic Jackpot: Why Our Universe Is Just Right for Life, New York, 2007, Orion Publications. p. 2

[14] Spyridon Kakos, What IS a particle? A surprisingly difficult (and immaterial) question, Harmonia Philosophica, Retrieved from http://harmonia-philosophica. blogspot.gr/2012/12/philosophy-wire-what-is-particle.html, 2017-12-01.

[15] Spyridon Kakos, Mind, Morphogenetic fields, Quantum physics, Harmonia Philosophica, Retrieved from http://harmonia-philosophica.blogspot.gr/2011/11/mindmorphogenetic-fields-quantum.html, 2017-12-01.

[16] Spyridon Kakos, NDE and other consciousness without brain references, Harmonia Philosophica, Retrieved from https://harmoniaphilosophica.wordpress.com/2013/07/ 24/near-death-experiences-nde-references/, 2017-12-01

[17] Spyridon Kakos, Non-local consciousness. Being God, Harmonia Philosophica, Retrieved from https://harmoniaphilosophica.wordpress.com/2013/09/24/non-localconcsiousness-being-god/, 2017-12-01.

[18] Paul K. Feyerabend, Farewell to Reason, 1987.

[19] Bertrand Conway, Galileo Galilei, Catholic Education Resource Center, Retrieved from https://www.catholiceducation.org/en/controversy/commonmisconceptions/galileo-galilei.html, 2017-12-01.

[20] Rev. Reuben Parsons, D.D., Some Lies and Errors of History, Notre Dame, Indiana: The Ave Maria, 7th edition, 1893, pp. 95-122. 
[21] Vic Biorseth, The Galileo Inquisition, Retrieved from https://www.catholicamericanthinker.com/the-galileo-inquisition.html, 2017-12-01.

[22] Peter Klein, The Galileo legend, Retrieved from https://organizationsandmarkets.com/2007/01/18/the-galileo-legend/, 2017-12-01.

[23] Martin Heidegger, Wikipedia article, Retrieved from https://en.wikipedia.org/wiki/Martin_Heidegger, 2017-12-01.

[24] The InterAcademy Partnership, IAP Statement on the Teaching of Evolution, Retrieved from http://www.interacademies.net/10878/13901.aspx, 2017-12-01

[25] World Values Survey Portal : Cross-reference "Importance of Religion" with "Highest education level attained", Years 2000-2004. 